University of Nebraska - Lincoln

DigitalCommons@University of Nebraska - Lincoln

Publications, Agencies and Staff of the U.S.

Department of Commerce

U.S. Department of Commerce

2011

Common bottlenose dolphins (Tursiops truncatus) in California waters: Cranial differentiation of coastal and offshore ecotypes

William F. Perrin

NOAA, william.perrin@noaa.gov

Janet L. Thieleking

NOAA

William A. Walker

NOAA

Frederick I. Archer

NOAA

Kelly M. Robertson

NOAA

Follow this and additional works at: https://digitalcommons.unl.edu/usdeptcommercepub

Part of the Environmental Sciences Commons

Perrin, William F.; Thieleking, Janet L.; Walker, William A.; Archer, Frederick I.; and Robertson, Kelly M., "Common bottlenose dolphins (Tursiops truncatus) in California waters: Cranial differentiation of coastal and offshore ecotypes" (2011). Publications, Agencies and Staff of the U.S. Department of Commerce. 305.

https://digitalcommons.unl.edu/usdeptcommercepub/305

This Article is brought to you for free and open access by the U.S. Department of Commerce at DigitalCommons@University of Nebraska - Lincoln. It has been accepted for inclusion in Publications, Agencies and Staff of the U.S. Department of Commerce by an authorized administrator of DigitalCommons@University of Nebraska - Lincoln. 


\title{
Common bottlenose dolphins (Tursiops truncatus) in California waters: Cranial differentiation of coastal and offshore ecotypes
}

\author{
WILLIAM F. PERRIN \\ JANET L. THIELEKING \\ Southwest Fisheries Science Center, \\ National Marine Fisheries Service, NOAA, \\ 3333 North Torrey Pines Court, \\ La Jolla, California 92037, U.S.A. \\ E-mail: william.perrin@noaa.gov \\ WiLLIAM A. WALKER \\ National Marine Mammal Laboratory, \\ Alaska Fisheries Science Center, \\ National Marine Fisheries Service, NOAA, \\ 7600 Sand Point Way N.E., \\ Seattle, Washington 98115, U.S.A. \\ FREDERICK I. ARCHER \\ KELLY M. ROBERTSON \\ Protected Resources Division \\ Southwest Fisheries Science Center, \\ National Marine Fisheries Service, NOAA, \\ 3333 North Torrey Pines Court, \\ La Jolla, California 92037, U.S.A.
}

\begin{abstract}
Coastal and offshore bottlenose dolphins in California waters are currently assessed and managed as separate stocks. Recent molecular studies (of mtDNA haplotypes and microsatellites) have shown the two populations to be genetically differentiated. This study investigated cranial osteological differentiation of the forms. The sample analyzed included 139 skulls from live captures, direct takes, fishery bycatch, and strandings; the skulls were assigned to form based on collection locality or mtDNA haplotype. The coastal form differs from the offshore form mainly in features associated with feeding: larger and fewer teeth, more robust rostrum, larger mandibular condyle, and larger temporal fossa. This suggests that it may feed on larger and tougher prey than the offshore form. Differences between the forms in other features of the skull may reflect differences in diving behavior and sound production. Approximately $86 \%$ of the stranded specimens were estimated to be of coastal origin; based on relative estimated sizes of the two populations and assuming similar mortality rates, this suggests that a coastal carcass is about 50 times more likely to beach than an offshore one. The morphological differences between the two
\end{abstract}


ecotypes indicate evolutionary adaptation to different environments and emphasize the importance of conserving the relatively small coastal population and its habitat.

Key words: osteology, Random Forest, sexual dimorphism, functional morphology, mtDNA, principal components analysis.

The taxonomic history of bottlenose dolphins in the eastern North Pacific is long and confused. Tursiops gillii was described from Monterey Bay (Dall 1873) based on a dolphin taken by Scammon (1874). T. пииапи was described from the far-offshore eastern tropical Pacific, at $12^{\circ} \mathrm{N}, 120^{\circ} \mathrm{W}$ (Andrews 1911). Hershkovitz (1966) synonymized the latter with Tursiops truncatus, assigning it to a subspecies T. t. aduncus, but recognized the former. More recent workers have considered all the bottlenose dolphins in the eastern Pacific, including the nominal species T. gillii and T. nuuanu, to belong to T. truncatus (Rice 1998, Perrin et al. 2009). Tursiops aduncus is now recognized as a separate species restricted to the western Pacific and Indian Oceans (Wang and Yang 2009).

Norris and Prescott (1961) first noted that bottlenose dolphins occur in both shallow inshore waters and bays and in deeper offshore waters of California. Based on experiences while capturing dolphins for exhibit, Walker (1975) suggested that these were separate populations. The existence of two populations or ecotypes has been widely recognized since he presented the results of a study of osteology, parasites, and stomach contents in an unpublished contract report (Walker 1981), and subsequent studies of distribution, behavior, ecology, physiology, population dynamics, and population size and status have proceeded on that assumption (Duffield et al. 1983; Hansen 1983, 1990; Wells et al. 1990; Barlow 1995; Forney et al. 1995; Carretta et al. 1998, 2009; Defran and Weller 1999; Defran et al. 1999; Dudzik 1999; Ward 1999). The coastal range extends from near San Francisco to south of the border along the coast of Baja California, Mexico and is thought to be restricted to within about $1 \mathrm{~km}$ of the mainland coast (Hansen 1990, Hansen and Defran 1990, Carretta et al. 1998, Defran and Weller 1999), with the animals typically encountered in water $<10$ m deep (Ward 1999). These dolphins are not highly philopatric, being found at different times nearly anywhere within their linear range (Hansen and Defran 1990, Hanson and Defran 1993, Carretta et al. 1998, Defran et al. 1999). Presumed offshore bottlenose dolphins occur in deeper water beyond $1 \mathrm{~km}$ from the coast, around the Channel Islands, and as far north as $41^{\circ} \mathrm{N}$ (Carretta et al. 2009). The coastal population off California is most recently estimated at 450-500 animals and the offshore population at 3,495 (CV = 0.43) (Dudzik et al. 2006).

Walker's (1981) sample of specimens included dolphins known to have been captured from around the Channel Islands and stranded dolphins recovered from mainland beaches and from the Gulf of California. Two clusters were evident in multivariate analyses of skull measurements, one containing the known offshore animals and the other the stranded specimens (including those from the Gulf of California), suggesting that all of the stranded dolphins were of coastal origin. The coastal animals had on the average larger teeth, greater proximal ramus height, and larger mandibular condyles. Walker also found differences in parasite faunas and stomach contents, with only the offshore dolphins containing mesopelagic prey.

Most recently, Lowther [Thieleking] (2006) found nonoverlapping mtDNA control-region haplotypes and differences in microsatellite frequencies for biopsy samples taken close to the coast (within $1 \mathrm{~km}$ ) vs. farther offshore. She also found 


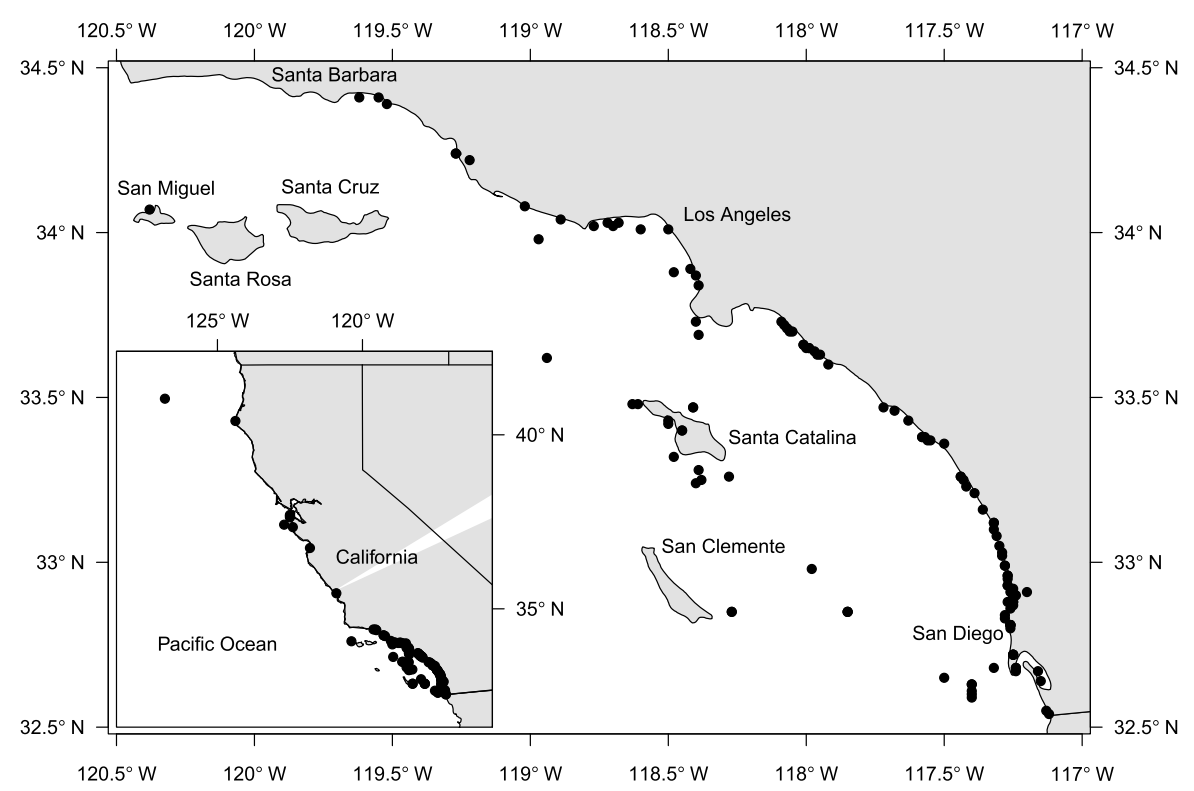

Figure 1. Map of localities of specimens and biopsy samples used in this study. Main map shows enlargement of Southern California Bight; inset shows entire distribution of sample localities. One symbol may represent more than one specimen. In addition, the sample included two dolphins captured from imprecisely recorded localities in the vicinity of the Channel Islands.

differentiation between coastal samples from California and samples from the Gulf of California, suggesting that they should not be considered to be from the same population.

In the present study, we extended the genetic analysis to include additional biopsies, dolphins live-captured for exhibit, a dolphin bycaught in an offshore fishery, and stranded dolphins. We also measured the much larger series of osteological specimens now available in U.S. museums. Based on the overall genetic patterns in the larger series, we examine morphology of the two ecotypes and estimate population membership for the adult specimens stranded on the mainland and lacking molecular assignments (not making the assumption that all were coastal dolphins). We discuss the ecologies of the forms in light of their morphological differences and estimate stranding rates for carcasses of the coastal and offshore ecotypes.

\section{METHODS}

\section{The Sample}

We examined 139 osteological specimens in museums and private collections that were collected between the 1850s and 2006 (Appendix 1) from the border with Mexico north to Cape Mendocino $\left(\sim 40^{\circ} \mathrm{N}\right)$ in California (Fig. 1). We excluded specimens from the Gulf of California because of Lowther's (2006) finding of genetic difference from California specimens. We excluded the few specimens available from 
the outer coast of Baja California because of uncertainty about the southern limit of the range of the population in California waters and the logistical difficulties of obtaining samples from those specimens for genetic analysis. Most of the specimens examined were from strandings (all but two that stranded on the Channel Islands were from the mainland). Sixteen were from dolphins live-captured offshore (in the vicinity of the Channel Islands) for exhibit at Marineland of the Pacific, and two were from dolphins live-captured in San Diego Bay. Seventy-four of the 139 California specimens were cranially adult, evidenced by the approximate criterion of distal fusion of the premaxillae and maxillae of $>1 \mathrm{~cm}$ (Mead and Potter 1990, Perrin and Heyning 1993); 65 were cranially juvenile. We collected teeth, bone, or softtissue samples from 131 specimens for genetic analysis. Powder from teeth and bone was collected by low speed drilling using the sterile technique described in Morin et al. (2006). The powder was stored at room temperature. When soft tissues were available, skin or muscle was collected and stored in a $20 \%$ salt-saturated solution of dimethyl sulfoxide (DMSO) and frozen at $-20^{\circ} \mathrm{C}$. DNA extraction and sequencing followed the protocols in Lowther (2006).

We were successful in extracting and sequencing mtDNA for 98 of the 131 samples; the sequence data were analyzed together with those from the 171 previously analyzed (Lowther 2006) or newly collected biopsy samples, for a total of 269. For the remaining 41 osteological specimens, all from strandings or captures on the mainland, either no tissue sample was collected or DNA extraction or sequencing failed. Coastal biopsy samples were from $<1 \mathrm{~km}$ from shore and offshore samples from beyond that limit.

\section{Morphometrics}

Cranial and postcranial measurements and tooth counts were taken with dial calipers and anthropometers by WFP and WAW as in Perrin (1975) with addition of three measurements: minimum palatal width anterior to the pterygoid hamuli (PALW), length of the left pterygoid hamulus (PTLN), and maximum dimension of the left mandibular condyle (MWMC). WFP and WAW measured a series of the same skulls to intercalibrate their methods. Measurements were made to the nearest millimeter except TOOW (diameter of tooth at mid-row), which was measured to the nearest tenth $\mathrm{mm}$. Counts of teeth or alveoli were made for both left and right upper and lower rows, and the highest upper (HIUP) and highest lower (HILO) counts were included in the analyses. When a count was available for only one side, it was used as an estimate of the highest count. Finally, we added a variable (MXTH) that was the maximum of HIUP and HILO; this variable was used only in the classification analyses.

\section{Genetic Analyses}

The 269 mtDNA control-region sequences were represented by 56 haplotypes. Of these, five haplotypes were from biopsied coastal dolphins and 34 were from offshore dolphins either biopsied, live-captured, bycaught in an offshore fishery, or stranded in the Channel Islands (Lowther 2006). We recovered 128 sequences, represented by 27 haplotypes, from stranded dolphins of unidentified ecotype. Of this set, 80 sequences and eight haplotypes corresponded to those from dolphins of only one known ecotype and were thus identified to the respective ecotype. The stranded 
dolphins having "new" haplotypes not retrieved from the known coastal or offshore dolphins or obtained from both ecotypes (only one haplotype) remained unidentified and were assigned to ecotype based on morphology with randomForest, as described further.

\section{Statistical Analyses}

Our first goal in the analyses was to characterize and compare the two series in terms of the individual measurements (recognizing that the variables are likely intercorrelated; see later). Because of larger size of the coastal series, we first examined sexual dimorphism in that series with permutation $t$-tests for each measurement separately. In each test, the observed difference in means between sexes for a measurement $(\Delta \mu)$ was compared to a distribution of differences generated under the null hypothesis of no dimorphism by randomly permuting each sample's assignment to sex in 1,000 iterations. Statistical significance was assessed as the proportion of iterations in which $\Delta \mu$ was greater or less than the observed $\Delta \mu$, depending on whether the observed value was greater or less than zero, respectively. Differences between ecotypes were examined with a second permutation test. For those measurements that showed significant sexual dimorphism in the coastal series in the first test, we conducted separate ecotype analyses for each sex. All analyses were conducted using R v.2.10.1 (R Development Core Team 2009).

We further compared the cranial measurements for the two series with a Bayesian approach. We only analyzed measurements for which we had more than three samples within each ecotype. We constructed uniform priors based on ranges reported for the cranial measurements and meristics in T. truncatus by True (1889), Ogawa (1938), Tomilin (1957), Hersh et al. (1990), Gao et al. (1995), Robineau and Vely (1997), Wang et al. (2000), and Kemper (2004). For all measurements, the mean ( $\mu$ ), and precision $\left(\tau=1 / \sigma^{2}\right)$ of a normal distribution were estimated. Each parameter was indexed by ecotype $(e)$ and sex $(s)$, producing the following likelihood function for the $i$ th sample:

$$
x_{i} \sim N\left(\mu_{e_{i} s_{i}}, \tau_{e_{i} s_{i}}\right) .
$$

Priors for precision $(\tau)$ were set to Gamma $\left(10^{-4}, 10^{-4}\right)$. MCMC runs for each measurement consisted of 100,000 burn-in iterations, followed by 10,000 sampling iterations, with samples collected from the posterior every 10th iteration. Eight independent MCMC chains were run for each measurement. Posteriors for the mean value of an ecotype were calculated as the weighted mean between the posteriors for each sex $\left(\mu_{e s=m}\right.$ and $\left.\mu_{e s=f}\right)$ with $\tau_{e s=m}$ and $\tau_{e s=f}$ as the respective weights. Posteriors for sexual dimorphism within an ecotype were the differences between the posteriors $\mu_{e s=m}$ and $\mu_{e s=f}$. Similarly, posteriors for differences among ecotypes were the difference between $\mu_{e=\text { offshore }}$ and $\mu_{e=\text { coastal }}$, with the geometric mean of $\tau_{e s=m}$ and $\tau_{e s=f}$ as the respective weights for each ecotype. The Bayesian analyses were conducted with the BRugs v.0.5-3 package in $\mathrm{R}$ (Lunn et al. 2009).

To assign specimens of unknown ecotype, we created a Random Forest (RF) (Breiman 2001) classifier using the randomForest v.4.5-34 package in $\mathrm{R}$ (Liaw and Wiener 2002). For the classifier, those adult specimens that had either been collected offshore, alive coastally, or were classified based on mtDNA haplotypes unique to one of the two ecotypes were used as the training data set. In the RF, we only used 
measurements which were missing in three or fewer of the unknowns, as we wanted to ensure that the classifier would work on most specimens. Thus, we ended up using all of the skull measurements and meristics except for TOOW. The "known" adult specimens used to create the classifier were restricted to those with no more than two skull measurements missing, for which there were 32 coastal and nine offshore skulls. Because of the disparity in sample size, we assigned priors (randomForest parameter classwt) to each sample as the inverse of their respective ecotype's sample size. We also conducted a conventional Linear Discriminant Analysis (LDA) but obtained higher accuracy of classification with RF (LDA data not shown). A second Random Forest classifier was constructed for juveniles and adult specimens that could not be classified in the first due to missing data. Only HILO and MXTH were used in this $\mathrm{RF}$ as these two variables were present for all samples but one. Using HIUP would have excluded eight more samples, and the remaining variables would have excluded the rest of the samples. Both adult and juvenile specimens of known ecotype were used in the training data. For the RF runs, the following parameter values were used: the number of variables sampled at each split $(m t r y)=13$, the number of trees in the Random Forest $(n t r e e)=20,000$, with all other parameters set to their defaults. The randomForest $\mathrm{R}$ objects used for classification are available from the authors upon request.

Because the cranial measurements are intercorrelated to varying degree (e.g., rostrum length is contained within overall skull length, and any suites of features involved in particular functions can be expected to be correlated), we also examined the data with principal component analysis (PCA) on all known and RF-classified adult specimens to determine positions of the specimens along major multivariate axes and to identify the variables most influential in separating any apparent clusters corresponding to the two ecotypes. PCA is a multivariate analysis without a priori identification of groups or clusters. All skull variables were used, and missing data were as imputed using the rfImpute function in the randomForest package with $m$ try $=13$, ntree $=10,000$, and classwt set to the inverse of the population frequency as in the classification RF.

Finally, we estimated the stranding frequency of offshore samples by conducting a bootstrap assignment procedure. In each of 1,000 iterations, stranded specimens with mtDNA haplotypes that were exclusive to an ecotype were automatically assigned to that ecotype. For those specimens with shared haplotypes or for which we did not have sequence data, ecotype assignment was based on each specimen's assignment probability from the RF analysis. The result of this procedure is a distribution of the fraction of assignments made to the offshore ecotype.

\section{RESULTS}

\section{Genetic Analyses}

We encountered 56 haplotypes: four only in the known coastal series, 33 only in the known offshore series, and 1 shared by both (Table 1). We assigned seven mainland-stranded specimens to the offshore ecotype and 73 to the coastal ecotype based on possession of a haplotype occurring only in the known-ecotype series. Stranded specimens possessing "new" haplotypes (not observed in either knownecotype series) or the single haplotype occurring in both series were considered to be of unknown ecotype for the morphological comparisons. 
Table 1. Frequency of mtDNA haplotypes in coastal, offshore, and mainland-stranded common bottlenose dolphins from California waters.

\begin{tabular}{|c|c|c|c|c|}
\hline Haplotype & GenBank Acc \# & Coastal & Offshore & Stranded \\
\hline CA_Ttru_01 & HQ206659 & 26 & 1 & 28 \\
\hline CA_Ttru_02 & HQ206660 & 16 & 0 & 31 \\
\hline CA_Ttru_03 & HQ206661 & 17 & 0 & 24 \\
\hline CA_Ttru_04 & HQ206662 & 6 & 0 & 15 \\
\hline CA_Ttru_05 & HQ206663 & 0 & 9 & 1 \\
\hline CA_Ttru_06 & HQ206664 & 4 & 0 & 3 \\
\hline CA_Ttru_07 & HQ206665 & 0 & 4 & 1 \\
\hline CA_Ttru_08 & HQ206666 & 0 & 3 & 2 \\
\hline CA_Ttru_09 & HQ206667 & 0 & 4 & 0 \\
\hline CA_Ttru_10 & HQ206668 & 0 & 4 & 0 \\
\hline CA_Ttru_11 & HQ206669 & 0 & 4 & 0 \\
\hline CA_Ttru_12 & HQ206670 & 0 & 2 & 2 \\
\hline CA_Ttru_13 & HQ206671 & 0 & 3 & 0 \\
\hline CA_Ttru_14 & HQ206672 & 0 & 3 & 0 \\
\hline CA_Ttru_15 & HQ206673 & 0 & 1 & 1 \\
\hline CA_Ttru_16 & HQ206674 & 0 & 2 & 0 \\
\hline CA_Ttru_17 & HQ206675 & 0 & 2 & 0 \\
\hline CA_Ttru_18 & HQ206676 & 0 & 2 & 0 \\
\hline CA_Ttru_19 & HQ206677 & 0 & 2 & 0 \\
\hline CA_Ttru_20 & HQ206678 & 0 & 2 & 0 \\
\hline CA_Ttru_21 & HQ206679 & 0 & 0 & 2 \\
\hline CA_Ttru_22 & HQ206680 & 0 & 2 & 0 \\
\hline CA_Ttru_23 & HQ206681 & 0 & 2 & 0 \\
\hline CA_Ttru_24 & HQ206682 & 0 & 2 & 0 \\
\hline CA_Ttru_25 & HQ206683 & 0 & 0 & 1 \\
\hline CA_Ttru_26 & HQ206684 & 0 & 0 & 1 \\
\hline CA_Ttru_27 & HQ206685 & 0 & 1 & 0 \\
\hline CA_Ttru_28 & HQ206686 & 0 & 1 & 0 \\
\hline CA_Ttru_29 & HQ206687 & 0 & 1 & 0 \\
\hline CA_Ttru_30 & HQ206688 & 0 & 0 & 1 \\
\hline CA_Ttru_31 & HQ206689 & 0 & 1 & 0 \\
\hline CA_Ttru_32 & HQ206690 & 0 & 0 & 1 \\
\hline CA_Ttru_33 & HQ206691 & 0 & 0 & 1 \\
\hline CA_Ttru_34 & HQ206692 & 0 & 0 & 1 \\
\hline CA_Ttru_35 & HQ206693 & 0 & 0 & 1 \\
\hline CA_Ttru_36 & HQ206694 & 0 & 1 & 0 \\
\hline CA_Ttru_37 & HQ206695 & 0 & 0 & 1 \\
\hline CA_Ttru_38 & HQ206696 & 0 & 1 & 0 \\
\hline CA_Ttru_39 & HQ206697 & 0 & 1 & 0 \\
\hline CA_Ttru_40 & HQ206698 & 0 & 0 & 1 \\
\hline CA_Ttru_41 & HQ206699 & 0 & 1 & 0 \\
\hline CA_Ttru_42 & HQ206700 & 0 & 0 & 1 \\
\hline CA_Ttru_43 & HQ206701 & 0 & 0 & 1 \\
\hline CA_Ttru_44 & HQ206702 & 0 & 1 & 0 \\
\hline CA_Ttru_45 & HQ206703 & 0 & 1 & 0 \\
\hline CA_Ttru_46 & HQ206704 & 0 & 0 & 1 \\
\hline CA_Ttru_47 & HQ206705 & 0 & 0 & 1 \\
\hline CA_Ttru_48 & HQ206706 & 0 & 1 & 0 \\
\hline
\end{tabular}

Continued 
Table 1. (Continued)

\begin{tabular}{lcccc}
\hline \hline Haplotype & GenBank Acc \# & Coastal & Offshore & Stranded \\
\hline CA_Ttru_49 & HQ206707 & 0 & 0 & 1 \\
CA_Ttru_50 & HQ206708 & 0 & 1 & 0 \\
CA_Ttru_51 & HQ206709 & 0 & 1 & 0 \\
CA_Ttru_52 & HQ206710 & 0 & 1 & 0 \\
CA_Ttru_53 & HQ206711 & 0 & 1 & 0 \\
CA_Ttru_54 & HQ206712 & 0 & 1 & 0 \\
CA_Ttru_55 & HQ206713 & 0 & 0 & 0 \\
CA_Ttru_56 & HQ206714 & 0 & 1 & 125 \\
Total & & 69 & 71 & \\
\hline
\end{tabular}

\section{T-test Comparisons}

In the coastal series, males were larger than females at $\alpha=0.05$ in 17 of the 28 cranial measurements. Females had a greater minimum width of the palate. The two sexes did not differ in number of teeth. Details of the analysis of dimorphism are given in Supporting Information Table S1. Comparison of the coastal and offshore series (Table 2) showed difference at $\alpha=0.05$ in 23 of the 28 measurements and both tooth counts. In both sexes, the coastal animals on average had a broader rostrum at the base, broader temporal fossa, shorter pterygoid hamulus, lesser minimum width of the palate, wider mandibular condyle, and about one tooth less in each row. Coastal females had a shorter overall skull length, shorter rostrum, shorter distance from rostrum tip to external nares and to internal nares, lesser parietal width, smaller antorbital process, shorter upper tooth row, longer lower tooth row, and shorter mandibular ramus. Coastal males had a broader rostrum at $1 / 2$ and $3 / 4$ length, broader external nares, greater zygomatic width, broader premaxillaries, deeper mandibular ramus, and larger teeth.

\section{Bayesian Analysis}

Posterior distributions of sexual dimorphism within each ecotype and example distributions of measurements showing the greatest differentiation between sexes are shown in Figure 2; the distributions for the other measurements and tooth counts are given in Supporting Information Figure S1. Males were larger than females with greater than $50 \%$ probability for 28 of 30 measurements in the coastal series and 11 in the offshore series. Offshore skulls were larger in 16 of 30 measurements. Considering those measurements with probabilities above about $80 \%$ and below about $20 \%$ in Figure 3, the offshore ecotype had a greater number of teeth (HIUP and HILO), longer rostrum (TIPP and ROST), greater palatal width (PALW), larger internal nares (INTN) and longer pterygoid hamuli (PTLN); and the coastal ecotype had larger mandibular condyles (MWMC), larger temporal fossa (FOSH), larger teeth (TOOW), greater postorbital width (POST), larger external nares (EXTN) and broader rostrum (ROSH and ROS3).

\section{Random Forest Classification of Adults}

The RF classifier for adult skulls (of known origin or with haplotype recorded from only either offshore or coastal) had an error rate of $3.6 \%$, correctly classifying 


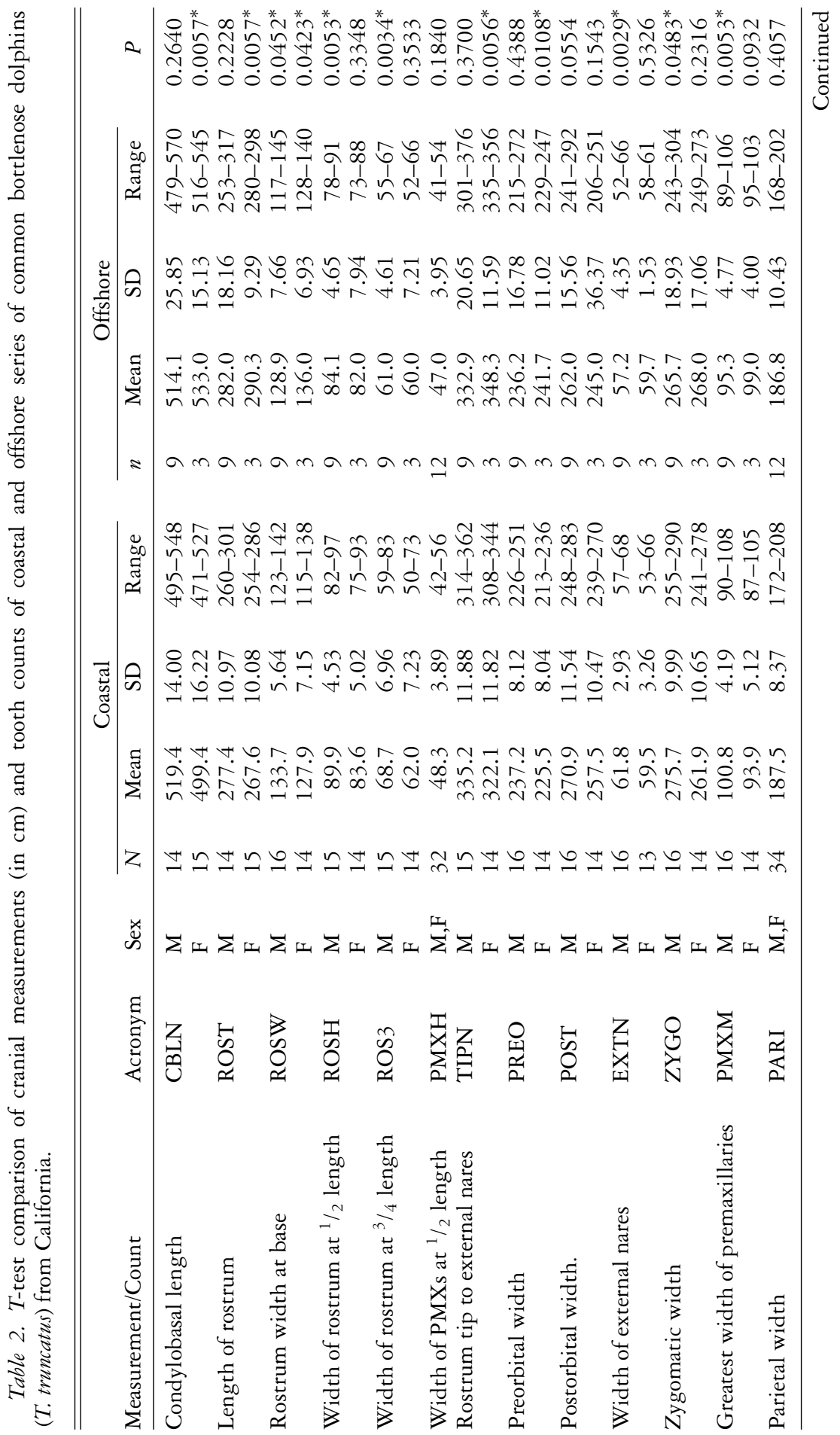




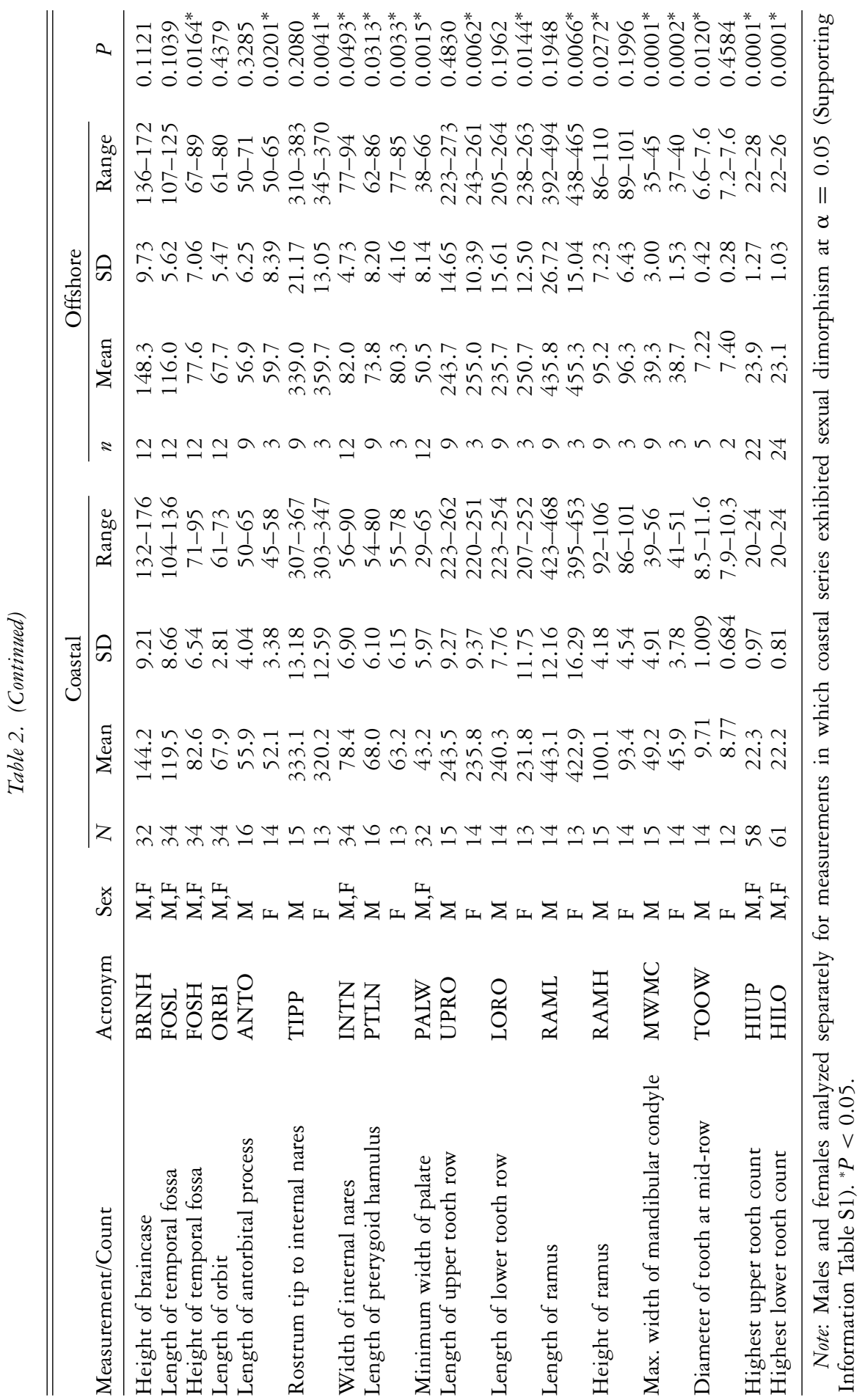



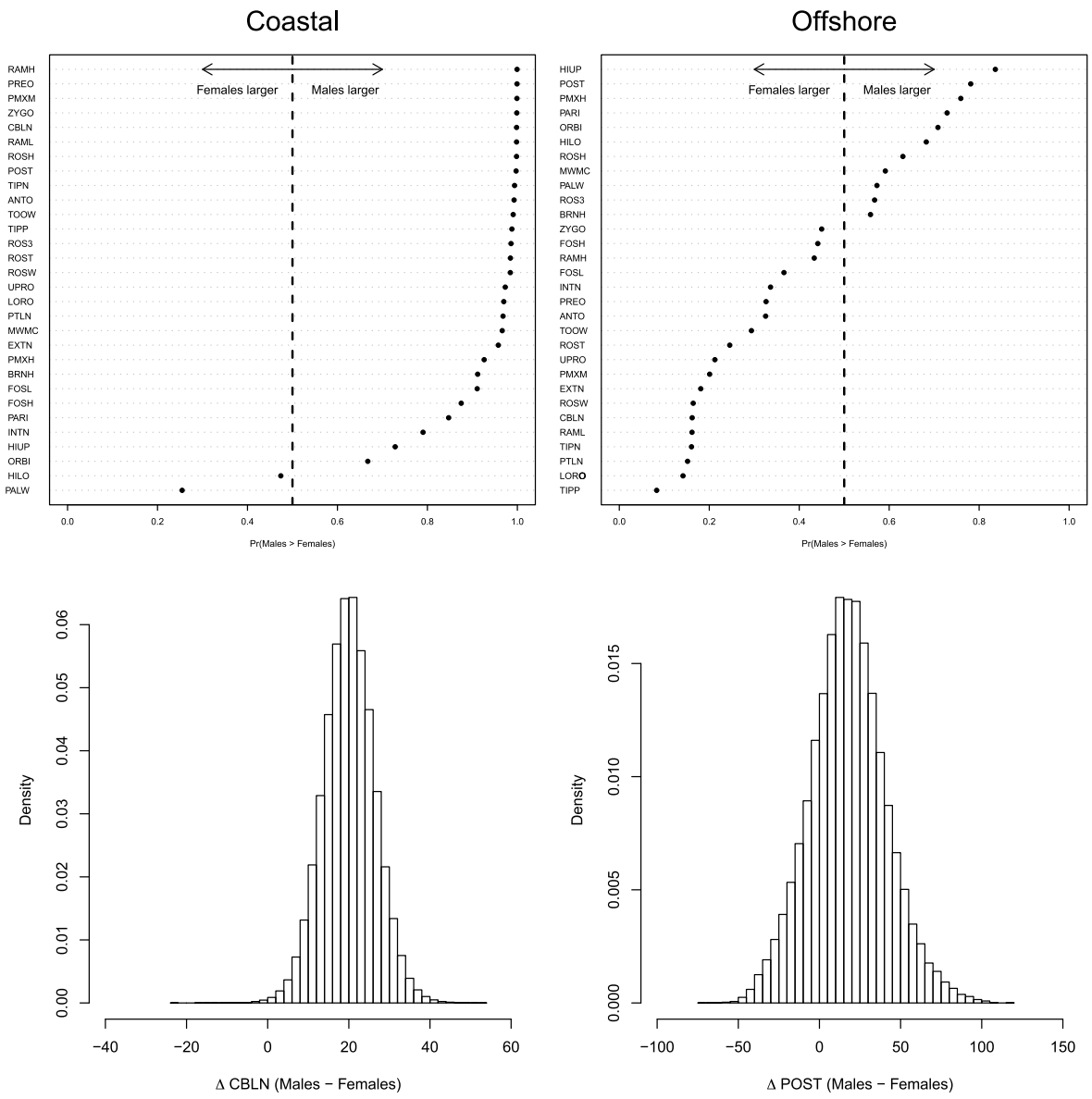

Figure 2. Posterior distributions of sexual dimorphism in coastal and offshore skulls. Upper panels shows probability of Males $>$ Females from posterior distributions of all measurements. Bottom panels show posterior distributions of sexual dimorphism for two extreme measurements in the two ecotypes. See Supporting Information Figure S1 for results for all variables.

all 21 coastal skulls and six of seven offshore skulls. The overall error rate for the secondary RF designed to classify juveniles and adults unclassifiable in the first was much larger at $38.8 \%$. However, the error rate for offshore specimens was far lower than for the first RF; it correctly classified 23 out of 24 skulls, vs. 29 out of 61 coastal skulls.

Figure 4 shows the distribution of assignment probabilities for skulls from mainland strandings after sequential use of the RF classifying algorithms. Under a rule in which assignments are accepted at probability $>0.5$, three of the 23 unknown adult skulls classifiable in the first RF would be classified as offshore and the remaining 20 as coastal (as shown in Fig. 4). If the assignment probability requirement were increased to $>0.75$, only two of these specimens would be assigned to offshore and 

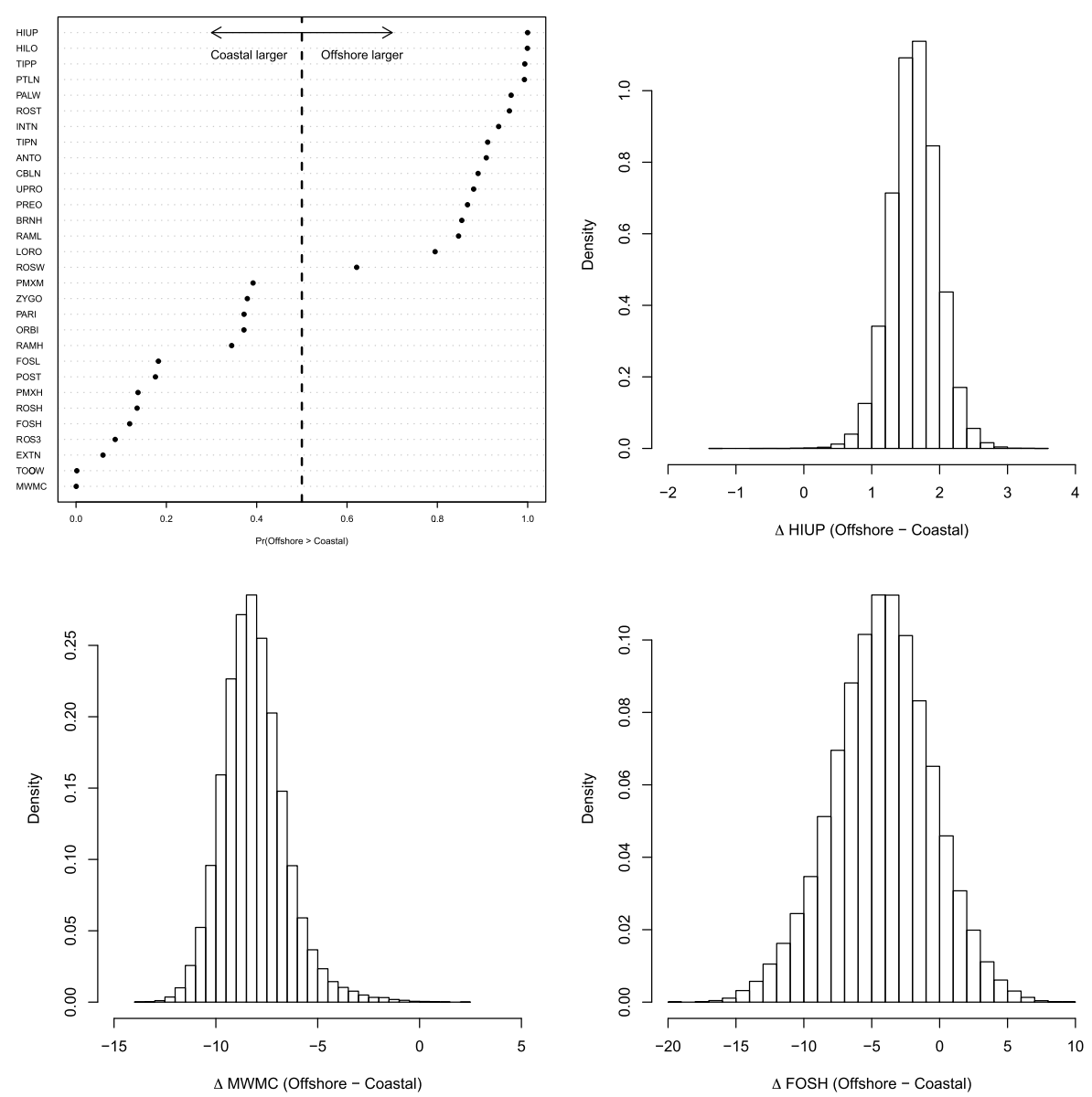

Figure 3. Posterior distributions for difference in means between ecotypes. Upper left panel shows probability of Offshore $>$ Coastal from posterior distributions of all measurements. Remaining three panels show posterior distributions of differences for extreme measurements where Offshore is larger (HIUP), or Coastal is larger (MWMC and FOSH). See Supporting Information Figure S1 for results for all variables.

19 to coastal. In total, assignment probabilities were generated for 48 of 49 stranded specimens that were not assignable based on unambiguous mtDNA haplotypes.

\section{Principal Components Analysis}

The first three components accounted for $67 \%$ of the variance. Loading coefficients for these components are given in Table 3. The coastal and offshore series overlapped almost completely for component 1 (Fig. 5) but showed strong separation for components 2 and 3 combined (Fig. 6). Measurements loading highest positively (defining offshore cluster) for both components 2 and 3 were the tooth counts (HIUP and HILO), palatal width (PALW) and length of the pterygoid hamuli (PTLN). Loading 

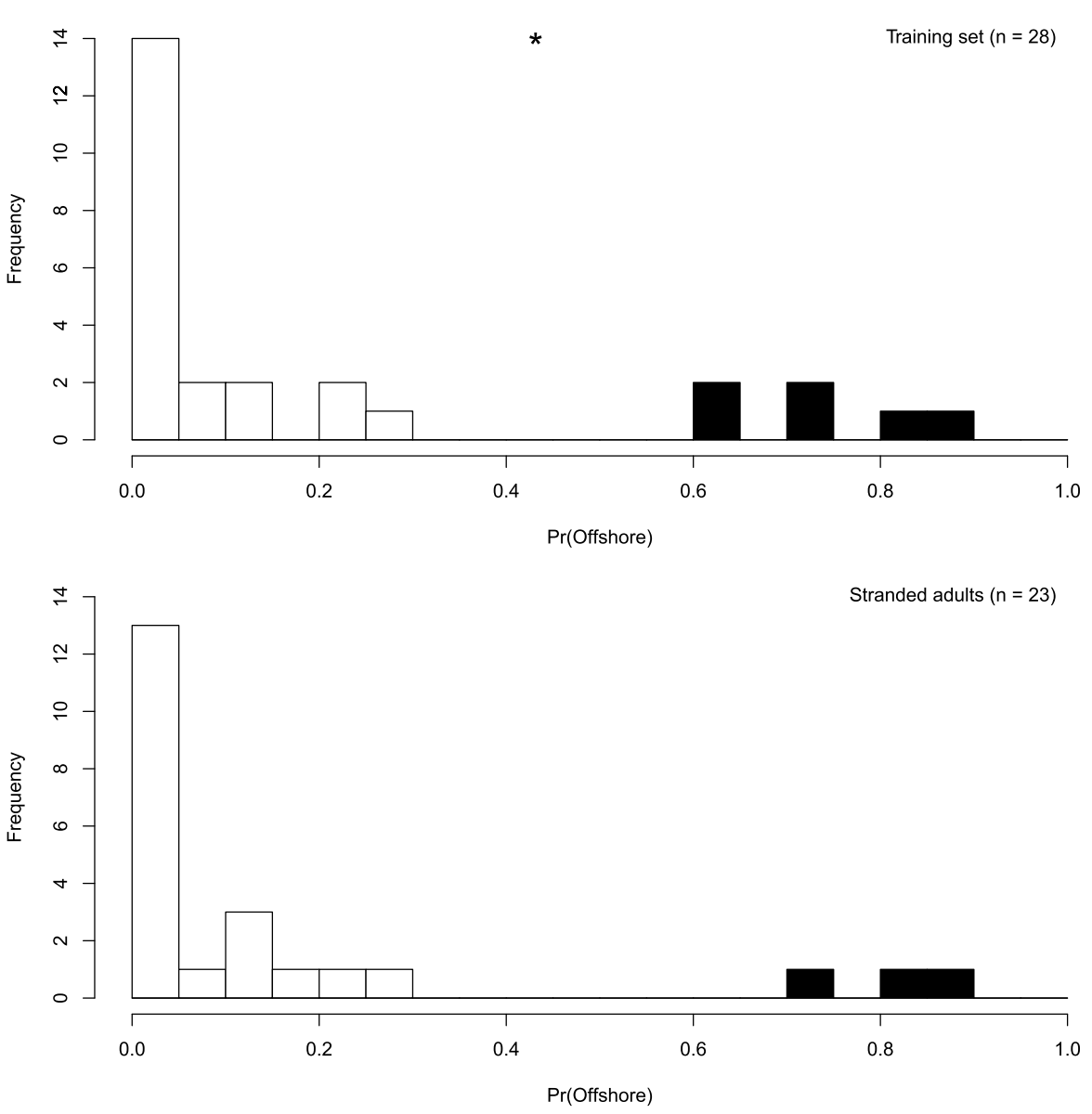

Figure 4. Distribution of assignment probabilities of adult skulls from the Random Forest analysis. Dark columns = known offshore (in upper panel) and assigned offshore with 50\% criterion (in lower panel). Asterisk indicates known offshore specimen misclassified as coastal in training data.

highest negatively (defining coastal cluster) were size of mandibular condyles (MWMC), tooth size (TOOW), and size of the external nares (EXTN). Females and males did not show substantial separation on any of the first four components (Supporting Information Fig. S2).

\section{Ecotype Composition of Mainland Strandings}

The RF assignment probabilities of the mainland-stranded skulls including juveniles and skulls not included in RF analysis because of missing data values provided estimates of offshore-ecotype membership ranging from near certainty (of coastal membership) to 0 (Fig. 7). From the bootstrap assignment analysis, the median probability of a stranded specimen being from the offshore ecotype is approximately 
Table 3. Variable loadings for first three Principal Components.

\begin{tabular}{lcrr}
\hline \hline Measurement/count & PC1 $(41 \%)$ & PC2 $(19 \%)$ & PC3 $(7 \%)$ \\
\hline CBLN & -0.237 & 0.166 & -0.163 \\
ROST & -0.194 & 0.259 & -0.189 \\
ROSW & -0.229 & -0.100 & 0.095 \\
ROSH & -0.204 & -0.187 & 0.162 \\
ROS3 & -0.182 & -0.229 & 0.099 \\
TIPN & -0.220 & 0.198 & -0.219 \\
PREO & -0.242 & -0.016 & 0.123 \\
POST & -0.192 & -0.153 & -0.039 \\
ZYGO & -0.245 & -0.099 & -0.004 \\
PMXM & -0.212 & -0.117 & -0.053 \\
PARI & -0.139 & -0.115 & 0.132 \\
FOSL & -0.182 & -0.179 & -0.020 \\
FOSH & -0.148 & -0.232 & 0.045 \\
ORBI & -0.084 & 0.008 & -0.080 \\
ANTO & -0.197 & 0.085 & 0.076 \\
INTN & -0.192 & 0.019 & 0.201 \\
UPRO & -0.195 & 0.224 & -0.255 \\
HIUP & -0.070 & 0.292 & 0.314 \\
RAMH & -0.226 & -0.141 & -0.008 \\
MWMC & -0.103 & -0.234 & -0.211 \\
MXTH & -0.068 & 0.287 & 0.325 \\
PMXH & -0.167 & -0.189 & 0.207 \\
EXTN & -0.127 & -0.175 & -0.142 \\
TIPP & -0.203 & 0.243 & -0.123 \\
LORO & -0.213 & 0.161 & -0.217 \\
RAML & -0.240 & 0.157 & -0.186 \\
BRNH & -0.162 & -0.141 & 0.235 \\
PALW & -0.101 & 0.110 & 0.347 \\
HILO & -0.053 & 0.234 & 0.210 \\
PTLN & -0.174 & 0.169 & 0.169 \\
TOOW & -0.069 & -0.174 & -0.174 \\
\hline & & &
\end{tabular}

Note: Percent of variance accounted for by each component in parentheses.

$14 \%(95 \% \mathrm{CI}=0.11-0.17)$, indicating that a majority of strandings were of the coastal ecotype (Fig. 8).

\section{DISCUSSION}

\section{Sexual Dimorphism}

The extent of sexual dimorphism in skull measurements and meristics documented here is comparable to that previously reported for the species for some regions and greater than reported for others. In multivariate analysis of stranded adults and juveniles from the Gulf of Mexico, adult bottlenose dolphins from Texas exhibited sexual dimorphism, but those from Florida did not (Turner and Worthy 2003); the Texas males and females differed in all but 6 of 35 measurements, similar to the $t$-test results for California coastal dolphins. In analyzing 32 cranial characters in 


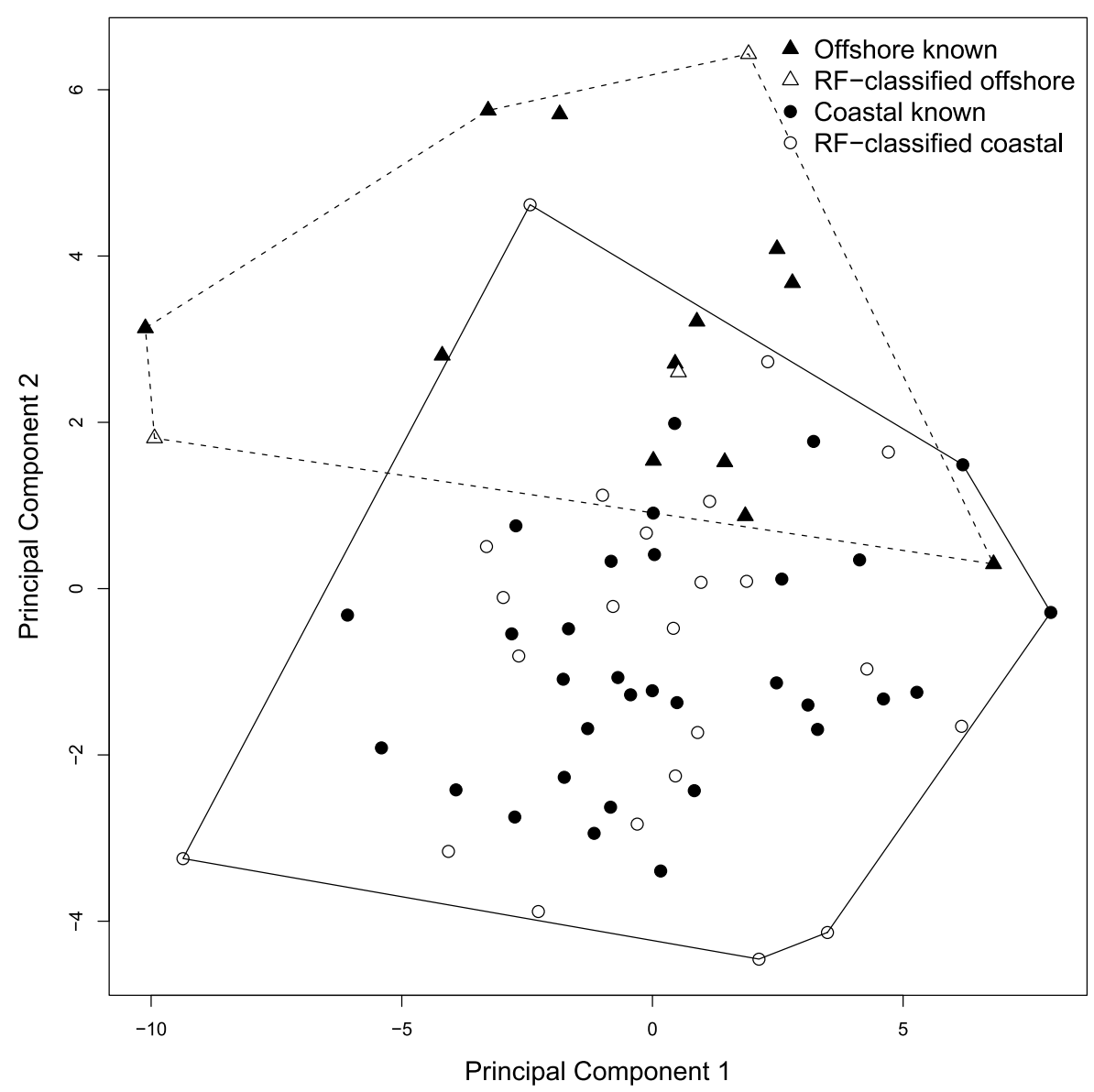

Figure 5. Distribution of adult skulls on first and second Principal Components. Skulls are identified to ecotype. RF-classified offshore/coastal = skulls assigned to offshore or coastal ecotype in the RF analysis based on morphology.

66 skulls, Hersh et al. (1990) found male common bottlenose dolphins from the coast of Florida to have on average about one more tooth in each row and parietal width a few millimeters greater than females. Their series did not differ in other features. Kemper (2004) found no significant differences between sexes in a mixed sample of 65 common bottlenose dolphins and Indo-Pacific bottlenose dolphins (T. aduncus) from South Australia, and Wang et al. (2000) found none in 17 males and 14 females from China. The collective results suggest that cranial sexual dimorphism is a geographically variable feature in the species. This variation may be related to variation in breeding system, as has been suggested for external dimorphism correlated with testis size in two forms of the spinner dolphin (Stenella longirostris) in the eastern tropical Pacific (Perrin and Mesnick 2003). Geographic variation in dimorphism occurs widely in mammals, reported recently for, among others, the spinner dolphin, S. longirostris (Perrin and Mesnick 2003), short-beaked common 


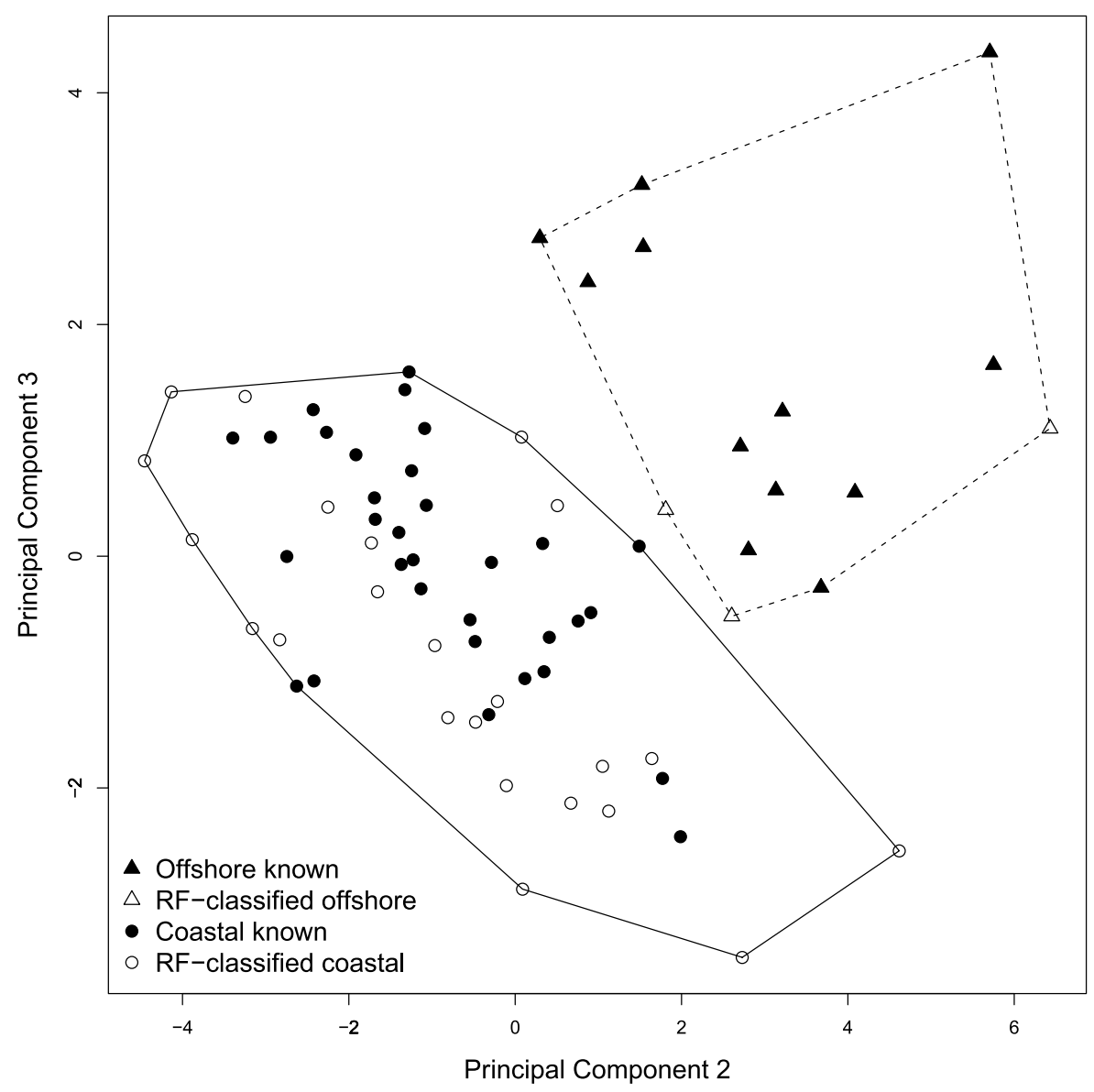

Figure 6. Distribution of adult skulls on second and third Principal Components. Skulls are identified to ecotype. RF-classified offshore/coastal $=$ skulls assigned to offshore or coastal ecotype in the RF analysis based on morphology.

dolphin, Delphinus delphis (Murphy et al. 2006), the polar bear, Ursus maritimus (Bechshoft et al. 2008), the black bear, Ursus americanus (Mahoney et al. 2001) and the common bushtail possum, Trichosurus vulpecula (Isaac and Johnson 2003) and correlated with variation in breeding system in the last.

\section{Morphological Differentiation and Functional/Ecological Implications}

Most differences between the coastal and offshore skulls are in features associated with feeding. The larger temporal fossa (origin of a larger temporal muscle yielding a stronger bite), stouter rostrum, more robust mandibular joint, and larger teeth of the coastal ecotype suggest that it may be more adapted to feeding on larger, tougher prey than the offshore ecotype. Perrin (1975) suggested a similar adaptation in tooth size and other features of the skull in the coastal subspecies of the pantropical 


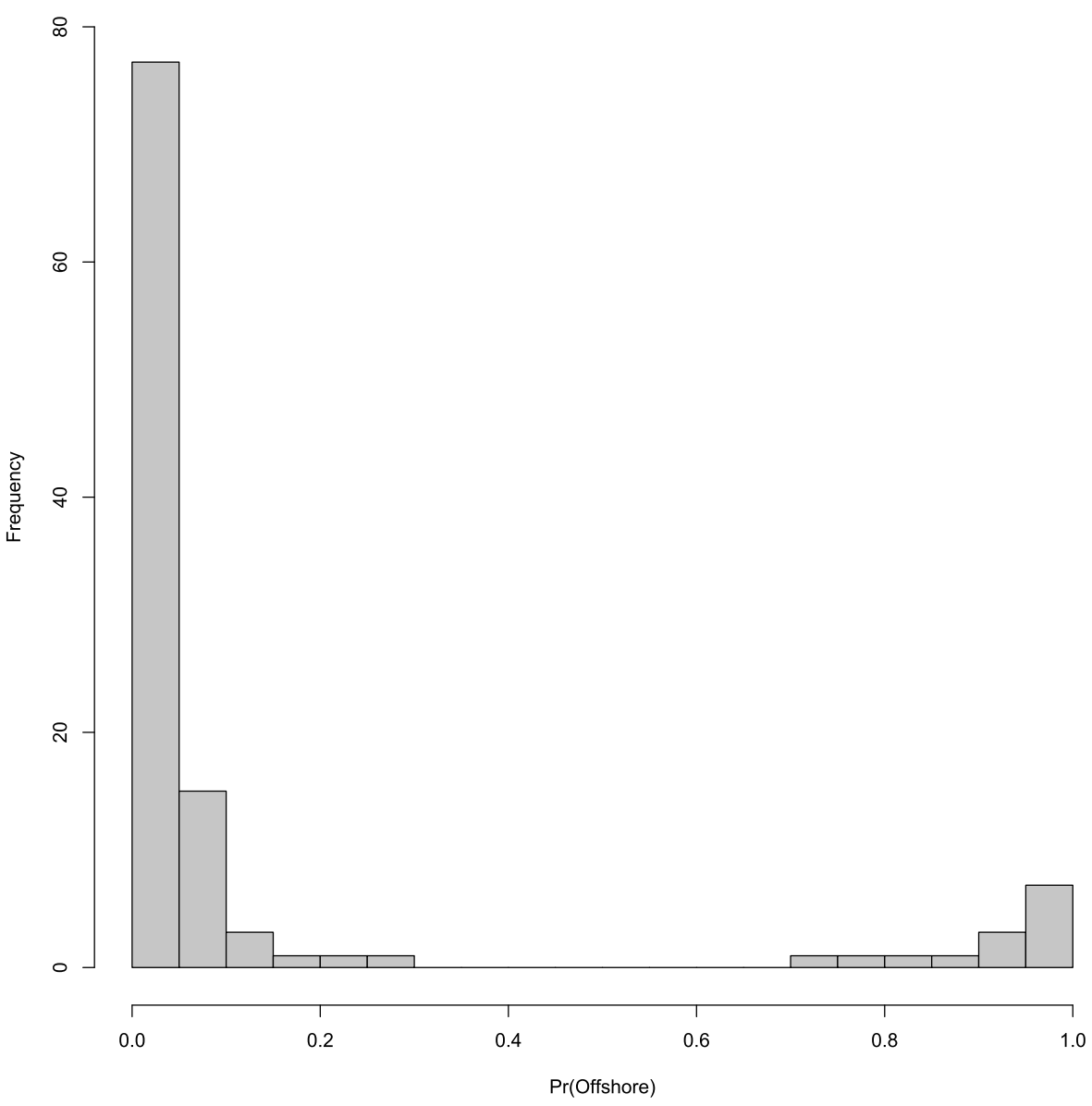

Figure 7. Distribution of assignment probabilities for all skulls from strandings. Assignment probabilities include those based on mtDNA sequence, and adult and juvenile assignments from the Random Forest analyses.

spotted dolphin, Stenella attenuata graffmani, of the eastern Pacific coast of tropical America; however, comparison of the diets of coastal and offshore spotted dolphins has not been carried out to confirm the hypothesis. A direct comparison of the diets of California coastal and offshore bottlenose dolphins is also lacking, but Walker (1981) reported that stomach contents of 17 pelagic bottlenose dolphins in the eastern tropical Pacific contained primarily small epipelagic and mesopelagic fishes (e.g., myctophids, melamphaeids, exocoetids, and small scombrids) and squids of various sizes, whereas nine stranded presumed coastal bottlenose dolphins from California (which may in fact have included some offshore dolphins; see earlier) included larger shallow-water and benthic fishes, such as sciaenids, batrachoidids, serranids, pomacentrids, and embiotocids, as well as smaller prey. A similar difference in stomach contents between coastal and offshore bottlenose dolphins was reported by Mead and Potter (1990) and by Van Waerebeek et al. (1990) for the western 


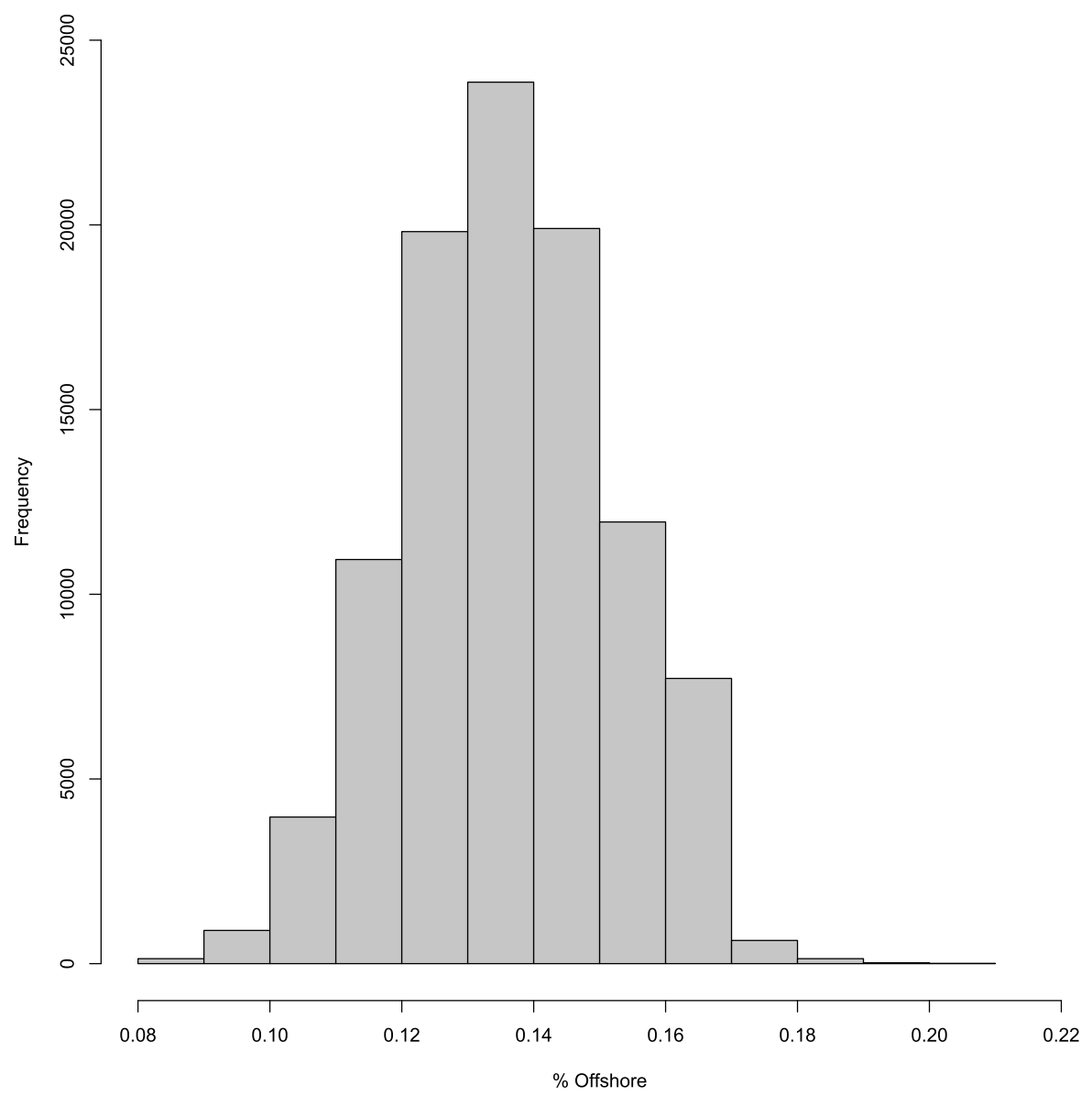

Figure 8. Distribution of $\operatorname{Pr}($ Offshore) from bootstrap analysis of assignment probabilities. Median $=0.14,95 \% \mathrm{CI}-0.11-0.17$.

Atlantic and Peru. The diet of the offshore ecotype in California waters may parallel that of the tropical eastern Pacific and eastern Atlantic and Peruvian pelagic animals in size and consistency of prey. Van Waerebeek et al. (1990) found coastal dolphins to have larger teeth than those from offshore in 19 bottlenose dolphins from Peru, a result similar to ours.

Rostral length (unlike rostral width) is not different between the two ecotypes, accounting for the lesser number of teeth in the coastal form (about two fewer in each row); larger teeth in the same linear space necessarily means fewer teeth.

The larger internal nares in the offshore ecotype (also reported by Mead and Potter [1995] for offshore vs. inshore bottlenose dolphins from the eastern Atlantic) may relate to efficiency of air exchange in deeper diving; deep diving by offshore bottlenose dolphins in the western Atlantic is suggested by hemoglobin profiles (Hersh and Duffield 1990) and telemetry data (Klatsky et al. 2007). The narrower width of the bony palate at the anterior terminus of the pterygoid hamuli (also reported by 
Mead and Potter 1990, for the offshore Atlantic dolphins) and the longer pterygoid hamuli may be involved in differential sound production used in tracking smaller and more elusive prey. The pterygoid hamulus in Delphinidae is excavated and inflated, containing an extension of the middle ear cavity, the pterygoid sinus (Fraser and Purves 1960). The elaborated pterygoid sinus is thought to insulate the ear from direct feedback through bony transmission of echolocation sounds produced in the dorsally located nasal sacs (Nummela 2009), and thus variation in extent of the pterygoid sinuses reflected in shape and size of the hamuli may indicate differentiation in echolocation or hearing.

\section{Difference in Stranding Rates}

Roughly $86 \%$ of bottlenose dolphins stranded on the mainland are estimated to be of the coastal ecotype. The ratio of offshore to coastal population size is approximately 7.4:1 (3,495/450-500; Carretta et al. 2009). If mortality rates were similar for the two ecotypes, this would imply that the probability of a carcass stranding on the mainland is roughly 50 times as great for the coastal ecotype as for the offshore ecotype. Although distance from shore and the effects of wind and currents could be expected to affect the probability of stranding, this difference seems inordinately great. If mortality rates were higher in the coastal ecotype (e.g., due to anthropogenic factors such as pollution: O'Shea et al. (1980) and Hansen (1990) reported that California coastal bottlenose dolphins had the highest levels of DDT contamination reported for any marine mammal), that would inflate the stranding ratio. Other factors that likely influence chances of strandings are scavenging of carcasses by sharks and simple decomposition leading to sinking; carcasses of offshore dolphins would be exposed to these factors longer than those of coastal dolphins.

\section{Caveats and Needed Research}

We have assumed that the bottlenose dolphins live-collected in the vicinity of the Channel Islands belong to an overall offshore population. This is consistent with the pattern of distribution of mtDNA haplotypes. However, it is possible that an island-associated population exists, separated to some extent from a larger offshore population in more pelagic waters. This possibility should be investigated with further biopsy sampling and analysis of mtDNA sequences and microsatellites.

In this study, bottlenose dolphins biopsied within one $\mathrm{km}$ of the shore were considered to be of the coastal ecotype and those biopsied farther offshore to be of the offshore ecotype. However, a longitudinal study of individually identified dolphins in central California (Santa Monica Bay and nearby areas) found that 31 of 406 dolphins that spent most of their time foraging $<1 \mathrm{~km}$ from shore (most often between 10 and $100 \mathrm{~m}$ from shore, in waters $<10 \mathrm{~m}$ deep) also occasionally ranged farther offshore for short periods, from 3 to $5 \mathrm{~km}$ from the coast (Bearzi et al. 2009). This suggests that the ranges of the two ecotypes overlap at least partially and at some times and that future genetic study and assignment of samples to ecotype should be combined with studies of individually identified dolphins. For the present study, the possible occasional spatial overlap in southern California could be expected to potentially lead to underestimation of differences because of possible misclassification of some biopsied dolphins sampled more than $1 \mathrm{~km}$ from shore. 
The ecological significance of the cranial differences between the coastal and offshore ecotypes can be further investigated by direct comparison of stomach contents of stranded animals classified to ecotype by genetic or morphological criteria.

We have assumed that mtDNA haplotypes unique to an ecotype are diagnostic of that ecotype. However, this assumption is entirely based on our set of samples, and further sampling may indicate that more of these haplotypes are shared among the ecotypes. This is especially true for the relatively lightly sampled offshore ecotype; it may not yet be adequately characterized. Development of assignment methods for haplotypes that incorporate such uncertainty is needed.

\section{Conservation and Management}

As noted by Bearzi et al. (2009), coastal dolphins are particularly susceptible to anthropogenic threats, including pollution by DDTs and other contaminants. The cranial differences between the coastal and offshore bottlenose dolphins described here suggest that the two ecotypes have adapted evolutionarily to different habitats. If the small coastal population were to be extirpated, it could not necessarily be expected that its habitat would be recolonized by the larger offshore population. This emphasizes the importance of protecting the coastal population and the quality of its habitat.

\section{ACKNOWLEDGMENTS}

We thank the curators and collection managers who gave us access to specimens and permission to extract teeth and bone samples for genetic analysis (and in some cases took skull measurements for us that we missed): Maureen Flannery, California Academy of Sciences; James Dines, David S. Janiger and the late John E. Heyning of the Los Angeles County Museum; Michelle Berman and Paul Collins of the Santa Barbara Museum of Natural History; Philip Unitt of the San Diego Natural History Museum; and James G. Mead and Charles W. Potter of the U.S. National Museum of Natural History. The stranded dolphins were collected off the beaches by the authors and Ray Bandar, Cathy Beck, Michelle Berman, Hannah J. Bernard, Robert L. Brownell, James M. Cotton, Kerri Danil, O. DeMaster, E. J. Dorfman, Raymond M. Gilmore, Larry J. Hansen, John R. Henderson, Mike Henshaw, John E. Heyning, Aleta A. Hohn, L. M. Huey, David S. Janiger, Jerry V. Kashiwada, Jay Kirkland, Mark S. Lowry, Tom D. Lewis, D. Luhrs, Edward D. Mitchell, S. F. Mochel, W. T. Norman, Kelly Robertson (Peltier), Charles M. Scammon, B. K. Seavey, J. Gurney Stoebe, Lee B. Vanderveld, and others whose names were not recorded. The manuscript was reviewed by Tomo Eguchi and David Weller, who offered useful suggestions for its improvement. Support for WAW was provided by the Southwest Fisheries Science Center (Order JG133F06SE1889).

\section{Literature Cited}

Andrews, R. C. 1911. Description of an apparently new porpoise of the genus Tursiops, with remarks upon a skull of Tursiops gillii Dall. Bulletin of the American Museum of Natural History 30:233-237.

Barlow, J. 1995. The abundance of cetaceans in California waters. Part I. Ship surveys in summer and fall of 1991. Fishery Bulletin 93:1-14.

Bearzi, M., C. A. Saylan and A. Hwang. 2009. Ecology and comparison of coastal and offshore bottlenose dolphins (Tursiops truncatus) in California. Marine and Freshwater Research 60:584-593. 
Bechshoft, T. Ø., C. Sonne, F. F. Rigét, Ø. Wiig and R. Dietz. 2008. Differences in growth, size and sexual dimorphism in skulls of East Greenland and Svalbard polar bears (Ursus maximus). Polar Biology 31:945-958.

Breiman, L. 2001. Random forests. Machine Learning 45:5-32.

Carretta, J. V., K. A. Forney and J. L. Laake. 1998. Abundance of southern California coastal bottlenose dolphins estimated from tandem aerial surveys. Marine Mammal Science 14:655-675.

Carretta, J. V., K. A. Forney, M. S. Lowry, et al. 2009. U.S. Pacific Marine Mammal Stock Assessments: 2008. NOAA Technical Memorandum NMFS NOAA-TM-NMFS-SWFSC434.

Dall, W. H. 1873. Description of three new species of Cetacea, from the coast of California. Proceedings of the California Academy of Sciences 5:12-14.

Defran, R. H., and D. W. Weller. 1999. Occurrence, distribution, site fidelity, and school size of bottlenose dolphins (Tursiops truncatus) off San Diego, California. Marine Mammal Science 15:366-380.

Defran, R. H., D. W. Weller, D. L. Kelly and M. A. Espinoza. 1999. Range characteristics of Pacific coast bottlenose dolphins (Tursiops truncatus) in the Southern California Bight. Marine Mammal Science 15:381-393.

Dudzik, K. J. 1999. Population dynamics of the Pacific coast bottlenose dolphins (Tursiops truncatus). Master's thesis, San Diego State University, San Diego, CA. 63 pp.

Dudzik, K. J., K. M. Baker and D. W. Weller. 2006. Mark-recapture abundance estimate of California coastal stock bottlenose dolphins: February 2004 to April 2005. SWFSC Administrative Report LJ-06-02 (unpublished), 15 pp. Contract report available from Southwest Fisheries Science Center, 3333 North Torrey Pines Court, La Jolla, CA 92037.

Duffield, D. A., S. H. Ridgway and L. H. Cornell. 1983. Hematology distinguishes coastal and offshore forms of dolphins (Tursiops). Canadian Journal of Zoology 61:930-933.

Forney, K. A., J. Barlow, and J. V. Carretta. 1995. The abundance of cetaceans in California waters. Part II. Aerial surveys in winter and spring of 1991 and 1992. Fishery Bulletin 93:15-26.

Fraser, F. C., and P. E. Purves. 1960. Hearing in cetaceans. Bulletin of the British Museum (Natural History), Zoology 7:1-140, plates 1-53.

Gao, A., K. Zhou and Y. Wang. 1995. Geographical variation in morphology of bottlenose dolphins (Tursiops sp.) in Chinese waters. Aquatic Mammals 21:121-135.

Hansen, L. J. 1983. Population biology of the coastal bottlenose dolphin (Tursiops truncatus) of southern California. Master's thesis, California State University, Sacramento, CA. 104 pp.

Hansen, L. J. 1990. California coastal bottlenose dolphins. Pages 403-420 in S. Leatherwood, and R. R. Reeves, eds. The bottlenose dolphin. Academic Press, San Diego, CA.

Hansen, L. J., and R. H. Defran. 1990. A comparison of photo-identification studies of California coastal bottlenose dolphins. Report of the International Whaling Commission (Special Issue 12): 101-104.

Hanson, M. T., and R. H. Defran. 1993. The behaviour and feeding ecology of the Pacific coast bottlenose dolphin, Tursiops truncatus. Aquatic Mammals 19:127-142.

Hersh, S. L., and D. A. Duffield. 1990. Distinction between northwest Atlantic offshore and coastal bottlenose dolphins based on hemoglobin profile and morphometry. Pages 129-139 in S. Leatherwood and R. R. Reeves, eds. The bottlenose dolphin. Academic Press, San Diego, CA.

Hersh, S. L., D. K. Odell and E. D. Asper. 1990. Sexual dimorphism in bottlenose dolphins from the east coast of Florida. Marine Mammal Science 6:305-315.

Hershkovitz, P. 1966. Catalog of living whales. U.S. National Museum Bulletin 246:1-259.

Isaac, J. L., and C. N. Johnson. 2003. Sexual dimorphism and synchrony of breeding: Variation in polygyny potential among populations in the common brushtail possum, Trichosurus vulpecula. Behavioral Ecology 14:818-822.

Kemper, C. M. 2004. Osteological variation and taxonomic affinities of bottlenose dolphins, Tursiops spp., from South Australia. Australian Journal of Zoology 52:29-48. 
Klatsky, L. J., R. S. Wells and J. C. Sweeney. 2007. Offshore bottlenose dolphins (Tursiops truncatus): Movement and dive behavior near the Bermuda pedestal. Journal of Mammalogy 88:59-66.

Liaw, A., and M. Wiener. 2002. Classification and regression by random forest. RNews $2 / 3: 18-22$

Lowther, J. L. 2006. Genetic variation of coastal and offshore bottlenose dolphins, Tursiops truncatus, in the eastern North Pacific Ocean. Master's thesis, University of San Diego, San Diego, CA. 126 pp.

Lunn, D., D. Spiegelhalter, A. Thomas and N. Best. 2009. The BUGS project: Evolution, critique and future directions (with discussion). Statistics in Medicine 28:3049-3082.

Mahoney, S. P., J. A. Virgl and K. Mawhinney. 2001. Potential mechanisms of phenotypic divergence in body size between Newfoundland and mainland black bear populations. Canadian Journal of Zoology 79:1650-1660.

Mead, J. G., and C. W. Potter. 1990. Natural history of bottlenose dolphins along the central Atlantic coast of the United States. Pages 165-195 in S. Leatherwood and R. R. Reeves, eds. The bottlenose dolphin. Academic Press, San Diego, CA.

Mead, J. G., and C. W. Potter. 1995. Recognizing two populations of the bottlenose dolphin (Tursiops truncatus) off the Atlantic coast of North America morphologic and ecologic considerations. IBI Reports (Japan) 5:31-44.

Morin, P. A., R. G. LeDuc, K. M. Robertson, N. M. Hedrick, W. F. Perrin, M. Etnier, P. Wade and B. L. Taylor. 2006. Genetic analysis of killer whale (Orcinus orca) historical bone and tooth samples to identify western U.S. ecotypes. Marine Mammal Science 22:897909.

Murphy, S., J. S. Herman, G. J. Pierce, E. Rogan and A. C. Kitchener. 2006. Taxonomic status and geographical cranial variation of common dolphins (Delphinus) in the eastern North Atlantic. Marine Mammal Science 22:573-599.

Norris, K. S., and J. H. Prescott. 1961. Observations on Pacific cetaceans of California and Mexican waters. University of California Publications in Zoology 63:291-402.

Nummela, S. 2009. Hearing. Pages 553-565 in W. F. Perrin, B. Würsig and J. G. M. Thewissen, eds. Encyclopedia of marine mammals. Academic Press, Amsterdam, The Netherlands.

Ogawa, T. 1938. Studien über die Zahnwale in Japan, insbesondere über die vier bei uns bisher unbekannten Gattungen Tursiops, Steno, Pseudorca und Mesoplodon. Arbeiten aus dem Anatomischen Institut der Kaiserlich-Japanischen Universität zu Sendai 21:173218 , plates $1-14$.

O'Shea, T. J., R. L. Brownell Jr., D. R. Clark Jr., W. A. Walker, M. L. Gay and T. G. Lamont. 1980. Organochlorine pollutants in small cetaceans from the Pacific and South Atlantic Oceans, November 1968-June 1976. Pesticides Monitoring Journal 14:35-46.

Perrin, W. F. 1975. Variation of spotted and spinner porpoise (genus Stenella) in the eastern Pacific and Hawaii. Bulletin of the Scripps Institution of Oceanography 21:1-206.

Perrin, W. F., and J. E. Heyning. 1993. Rostral fusion as a criterion of cranial maturity in the common dolphin, Delphinus delphis. Marine Mammal Science 9:195-197.

Perrin, W. F., and S. L. Mesnick. 2003. Sexual ecology of the spinner dolphin (Stenella longirostris). Marine Mammal Science 19:462-483.

Perrin, W. F., B. Würsig and J. G. M. Thewissen. 2009. Encyclopedia of marine mammals. 2nd edition. Academic Press, Amsterdam, The Netherlands.

R Development Core Team. 2009. R: A language and environment for statistical computing. R Foundation for Statistical Computing, Vienna, Austria.

Rice, D. W. 1998. Marine mammals of the world. Systematics and distribution. Society for Marine Mammalogy Special Publication Number 4. $231 \mathrm{pp}$.

Robineau, D., and M. Vely. 1997. Données preliminaries (taille corporelle, craniométrie) sur le grand dauphin (Tursiops truncatus) des côtes d'Afrique du nord-ouest (Mauritanie, Sénégal). Mammalia 61:443-448.

Scammon, C. M. 1874. The marine mammals of the north-western coast of North America. Carmany, San Francisco, CA. 
Tomilin, A. G. 1957. Cetacea. Volume 9 in V. G. Heptner, ed., Mammals of the U.S.S.R. and adjacent countries. Mammals of eastern Europe and adjacent countries. Akademi Nauk, Moscow, Russia.

Turner, J. P., and G. A. J. Worthy. 2003. Skull morphometry of bottlenose dolphins (Tursiops truncatus) from the Gulf of Mexico. Journal of Mammalogy 84:665-672.

True, F. W. 1889. Contributions to the natural history of the cetaceans, a review of the family Delphinidae. U.S. National Museum Bulletin 36:1-191, plates 1-42.

Van Waerebeek, K., J. C. Reyes, A. J. Read and J. S. McKinnon. 1990. Preliminary observations of bottlenose dolphins from the Pacific coast of South America. Pages 143-154 in S. Leatherwood and R. R. Reeves, eds. The bottlenose dolphin. Academic Press, San Diego, CA.

Walker, W. A. 1975. Review of the live-capture fishery for smaller cetaceans taken in southern California waters for public display, 1966-73. Journal of the Fisheries Research Board of Canada 32:1197-1211.

Walker, W. A. 1981. Geographic variation in morphology and biology of bottlenose dolphins (Tursiops) in the eastern North Pacific. Southwest Fisheries Center Administrative Report LJ-81-03C (unpublished), 52 pp. Contract report available from Southwest Fisheries Science Center, 3333 North Torrey Pines Court, La Jolla, California 92037, U.S.A.

Wang, J. Y., and S. C. Yang. 2009. Indo-Pacific bottlenose dolphin. Pages 602-608 in W. F. Perrin, B. Würsig and J. G. M. Thewissen, eds. Encyclopedia of marine mammals. Academic Press, Amsterdam, The Netherlands.

Wang, J. Y., L.-S. Chou and B. N. White. 2000. Osteological differences between two sympatric forms of bottlenose dolphins (genus Tursiops) in Chinese waters. Journal of Zoology, London 252:147-162.

Ward, B. G. 1999. Movement patterns and feeding ecology of the Pacific coast bottlenose dolphin (Tursiops truncatus). Master's thesis, San Diego State University, San Diego, CA. 98 pp.

Wells, R. S., L. J. Hansen, A. Baldridge, T. P. Dohl, D. L. Kelly and R. H. Defran. 1990. Northward extension of the range of bottlenose dolphins along the California coast. Pages 421-431 in S. Leatherwood and R. R. Reeves, eds. The bottlenose dolphin. Academic Press, San Diego, CA.

Received: 22 June 2010

Accepted: 4 September 2010

\section{APPENDIX 1}

Osteological specimens examined (Additional information on the specimens in Table S1):

CAS 22280, 23152, 23911, 25426, 26901, 26910, 27863; LACM 27094, 27401, 31426, 54638, 54639, 72294, 72295, 72493, 72549, 72552, 84028, 84029, 84031, 84032, 84033, 84034, 84036, 84055, 84056, 84058, 84059, 84065. 84097, 84119, 84120, 84164, 84194, 84242, 84248, 84250, 84267, 84269, 84270, 84271, 84276, 84285, 84292, 84293, 84294, 84957, 86022, 86024, 86091, 88905, 88918, 88925, 88942, 88983, 88984, 91309, 91320, 91781, 91862, 91886, 91913, 91936, 91958 , 91994, 92014, 92043, 92069, 92072, 95350, 95366, 95387, 95391, 95459, 95471, 95483, 95509, 95510, 95518, 95527, 95662, 95664, 95685, 95828, 95953, 95956, 95967; MCZ 49082, 49083; SBMNH 2970, 2971, 2972, 2973, 3090, 3334, 3532, $3536,3537,3538,3539,3540,3541,3543,3544,3546,3547,3553,3555$, 3618, 3662, 3669, 4066, 4944; SDNHM 11102, 20143, 20144, 20145, 21212, 21213, 23334; SWFSC 58, 95; USNM 298239, 395924, 500851, 504353, 504844, 
550011, 550012, 550021, 550023, 550097, 550125, 550193, 550194, 550919, A13022 ${ }^{1}$; Walker 159.

Museum and collection acronyms: CAS $=$ California Academy of Sciences, San Francisco, CA; LACM = Los Angeles County Museum, Los Angeles, CA; MCZ = Museum of Comparative Anatomy, Cambridge, MA; SBMNH = Santa Barbara Museum of Natural History, Santa Barbara, CA; SDNMH = San Diego Natural History Museum, San Diego, CA; SWFSC $=$ Southwest Fisheries Science Center, La Jolla, CA; USNM = U. S. National Museum of Natural History, Smithsonian Institution, Washington, DC; Walker = private collection of W. A. Walker.

\section{SUPPORTING INFORMATION}

Additional supporting information may be found in the online version of this article:

Figure S1. Posterior distributions of means from Bayesian analyses. Variable abbreviation is given in title with total sample size in parentheses. Posteriors of dimorphism ("coastal.dimorph" and "offshore.dimorph") are defined as male-female means. Posterior of difference between ecotypes ("ecotype.diff") is defined as offshore-coastal mean as described in the Methods section.

Figure S2. Distributions of male (solid) and female (dashed) scores for first four Principal Components.

Table S1. Osteological specimens included, with collector's field number, SWFSC laboratory identification number for samples for which tissue (skin, tooth or bone) available for DNA extraction, haplotype from successful extractions (see Table 1), known ecotype stratum upon entry into RF (see text), and origin (stranding, live capture, fishery bycatch, or "taken"). Stratum in brackets for specimens assigned to ecotype solely on basis of haplotype.

Table S2. T-test comparison of cranial measurements (in $\mathrm{cm}$ ) and tooth counts of female and male series of coastal common bottlenose dolphins (Tursiops truncatus) from California. $P<0.05$ in bold.

\footnotetext{
${ }^{1}$ Holotype specimen of Tursiops gillii Dall, 1873; mandible only from dolphin taken by Scammon near Monterey (Scammon 1874).
} 